\title{
Thermodynamics of Room Temperature Ionic Liquid $\mathrm{BMIInCl}_{4}$
}

\author{
Jinsong Gui \\ College of pharmacy, Guilin medical college \\ PO box 541004, Guilin, China \\ Tel: 86-773-589-1689 E-mail: jinsonggui@163.com \\ Kaimei Zhu (Corresponding author) \\ College of pharmacy, Guilin medical college \\ PO box 541004, Guilin, China
}

Tel: 86-773-589-1689Ｅ-mail: jinsonggui@glmc.edu.cn

The research is financed by Technical attack and new trial production (No. Gui Kegong 0815005-1-17) \&Guangxi natural sciences fund (No. Gui Kezi 0728229).

\begin{abstract}
In a room temperature ionic liquid RTILs) BMIInCl4, he equilibrium constants were determined potentiometrically for the dissociation reaction: $2 \mathrm{InCl} 4-=\mathrm{In} 2 \mathrm{Cl} 17-+\mathrm{Cl}-$ in the temperature range $313-348 \mathrm{~K}$. The equilibrium constants $\mathrm{K}=[\mathrm{Cl}-][\mathrm{In} 2 \mathrm{Cl} 7-] /[\mathrm{InCl} 4-] 2, \mathrm{pK}=76.43-780.9 / \mathrm{T}-0.115 \mathrm{~T}$ on different temperature. According to the thermodynamic relationship and the parameters of above equation, the dissociation entropy was determined.
\end{abstract}

Keywords: Thermodynamics, Equilibrium constants, BMIInCl4

\section{Introduction}

RTILs have received more attention because of their unusual properties lately . Sedon $(1997,68,351-356)$ and Gui (2010,84,760-765) reported that they have great potential as "green" solvents for industrial processes. It has been reported previously that the RTIL based on AlCl3 have been most widely studied (Endres, 2002,3, 144-154 and Ito, 2000,45,2611-22). However, there have been numerous studies in which transition metal chlorides were placed in RTILs for a variety of purposes. Hussey(1988,60,1763-1772) pointed out that $\mathrm{InCl} 3$ behaves much like $\mathrm{AlCl} 3$, that is, when the ratio of $\mathrm{InCl} 3$ to $\mathrm{BMIC}$ was equal to 1:1, InCl4- was main anion; when the ratio exceeded 1:1 anion In2Cl7- formed and when the ratio was less 1:1 some Cl- remained. In this paper RTILs BMIInCl4 was prepared .According Osteryoung' method(1979, 18, 1603-1605), on the temperature range of 313-348 K, the equilibrium constant $\mathrm{K}$ of the dissociation reaction was measured by following cell with liquid junction:

In $\mid$ InCl3-BMIC(ref) |fritted disk |BMIC-InCl3(x)| In

In $-3 \mathrm{e} \rightarrow \operatorname{In} 3+$

In $3++4 \mathrm{Cl}-\rightarrow$ InCl4-

2InCl4- = In2Cl7- + Cl-

$\mathrm{K}^{\prime}=[\mathrm{InCl} 4-] /[\mathrm{Cl} 4-] 4[\mathrm{In} 3+]$

$\mathrm{E}=(\mathrm{RT} / 3 \mathrm{~F}) \ln [\mathrm{In} 3+] /[\operatorname{In} 3+(\mathrm{ref})]$

$\mathrm{E}=(\mathrm{RT} / 3 \mathrm{~F}) \ln [\mathrm{InCl} 4-(\mathrm{ref})] /[\mathrm{InCl} 4-]+(4 \mathrm{RT} / 3 \mathrm{~F}) \ln [\mathrm{Cl}-] /[\mathrm{Cl}-(\mathrm{ref})]$

Where [ ] means a new concentration scale, which is defined that the number of moles of the species per kilogram melt .Where (ref) means reference one, $\mathrm{x}$ means mole fraction of $\mathrm{InCl} 3$ in $\mathrm{InCl} 3$ and $\mathrm{BMIC}$ mixture, Indium electrode was regarded as a reversible one and its electrode reaction is above.Corresponding Nernst Equation of this cell is received.Where E means emf of cell, $[\operatorname{In} 3+(\mathrm{ref})]$ and $[\operatorname{In} 3+]$ are activity of In3+ in reference electrode compartment and in working electrode compartment, respectively. It is noted that liquid junction potential Ej across the fritted disk may be neglected by Torsi(1971,10,1900-1902)

Through a series of the substitution of equation into equation, a pCl- electrode was yield.Hence, in this case, working electrode in the cell may be used as a pCl- one. Our purpose in the paper is to calculate the dissociation constant $\mathrm{K}$ and to obtain the dependence of $\mathrm{pK}$ on $\mathrm{T}$. Considering the dissociation reaction, other thermodynamic quantities were obtained. 


\section{Experimental}

\subsection{Reagente}

1-methylimidazole(AR grade reagent ACROS) and chlorobutane (AR grade reagent, Beijing Chem. Co) were used as received. The purity of Indium as reference electrode is 0.9999 produced from Kermio. Chem. Co, Tianjin. Ethyl acetate and acetonitrile were distilled and then stored over molecular sieves in tightly sealed glass bottles, respectively. Anhydrous $\mathrm{InCl} 3$ was purchased from Aldrich, opened in the glove box filled with dry argon, and used without further purification.

\subsection{Preparation of 1-methyl-3-butylimidazole chloride}

1-methyl-3-butylimidazole chloride (BMIC) was synthesized by refluxing the 1-methylimidazole with a large excess four double of chlorobutane at $323 \mathrm{~K}$ for $4 \mathrm{~h}$ and react $20 \mathrm{~h}$ at room temperature. Then the excess cholrobutane was removed by evaporation and the crude product was recrystalized from acetonitrile/ethylacetate. The resulting white precipitate was isolated filtration and then dried in vacuo for $20 \mathrm{~h}$. The $\mathrm{mp}$ of the product is (T-273)=66-68K.NMR spectrum is good agreement with the literature of Dyson(1997,3465-9) and Yang et al (2004, 6: 541-543).

\subsection{Prepareation of ionic liquid}

All glasswares that contacted the RTLI were cleaned in hot dilution nitric acid and washed in doublely deionized water, and then were backed dry in 393k over and stored in desiccator before use. In the cell in a dry agon atmosphere glove box, BMIC were firstly prepared. $\mathrm{InCl} 3$ mole fraction $\mathrm{X}=0.48$ was simple added to cell. In order to avoid thermal decomposition, the ieces of InCl3 added slowly, with stirring. The ionic liquid was formed and was brown.

\subsection{Procedure of the titration}

The electrochemical cell was made of Pyrex, which employed for the potentiometric titrations. The reference electrode compartment, containing $\mathrm{X}=0.48 \mathrm{InCl} 3$ ionic liquid of $\mathrm{BMIInCl} 4$ as electrolyte and coiled polishing Indium wire as reference electrode, was isolated with a fritted Pyrex disk. The electrolyte level in the reference electrode compartment was maintained very slightly higher than that of bulk solution. Initial bulk cell solution is the same with that in reference electrode compartment.

Equilibrium was reached about $1 \mathrm{~h}$ after each addition of $\mathrm{InCl} 3$. The potentials of cell were measured at the 313.15 , $323.15,333.15$ and $343.15,348.15 \mathrm{~K}$ by means of a SDC- II type digital potentiometer calibrated. The criterion for the attainment of equilibrium was taken a steady reading within $\pm 0.5 \mathrm{mv}$ for a period of about 0.5 minute. The emf was measured.

\section{Results and Discussion}

The values of cell emfs in the temperature range of $313.15 \mathrm{~K}$ to $348.15 \mathrm{~K}$ are listed in Table 1 , where each one is the average of four readings. Table 1 illustrate the results of experimental titrations from approximately $\mathrm{XInCl} 3=0.48$ to 0.55 in ionic liquid. The overall features of the titration jump is distinct from those obtained resulting in a greater pCl- range. When the composition range was near 50.00 mole \% $\mathrm{InCl} 3$, that is titration jump just. When composes $\mathrm{XInCl} 3=(50.0 \pm 0.2) \%$, in the system, activity coefficient and the activity of working electrode and reference electrode were approximately equal, the first item may ignore in the eq. $\mathrm{E}=(\mathrm{RT} / 3 \mathrm{~F}) \ln [\mathrm{InCl} 4-(\mathrm{ref})] /[\mathrm{InCl} 4-]+$ $(4 \mathrm{RT} / 3 \mathrm{~F}) \ln [\mathrm{Cl}-] /[\mathrm{Cl}-(\mathrm{ref})]$. Then emf $\mathrm{E}$ for the cell was given by $\mathrm{E}=(4 \mathrm{RT} / 3 \mathrm{~F}) \ln [\mathrm{Cl}-] /[\mathrm{Cl}-(\mathrm{ref})]$.The number of moles of $\mathrm{InCl} 3$ added to reach the midpoint of the titration curve was taken to be equal to number of moles of free $\mathrm{Cl}$ - initialling in BMIC.With this information, using E, the [Cl-] at the equivalence point was calculated. At the equivalence point [Cl-]=[In2Cl7-].Since [InCl4-] is known, that is,[InCl4-] $=$ number of moles of mass of melt. The unite of mass was kilogram. Then the dissociation constant, $\mathrm{K}=[\mathrm{Cl}-][\mathrm{In} 2 \mathrm{Cl} 7-] /[\mathrm{InCl}-\mathrm{H}] 2$, was to be calculated.

$\mathrm{pK}=-\operatorname{lgK}$, and were readly calculated with $\mathrm{K}=[\mathrm{Cl}-][\mathrm{In} 2 \mathrm{Cl} 7-] /[\mathrm{InCl} 4-] 2$ (note that $\mathrm{K}$ expressed as above is numberically the same on other concentration scales). The values of $\mathrm{pK}$ in the temperature range $313.15-348.15 \mathrm{~K}$ are fitted with the method of least squares with empirical equation of the form.So $\mathrm{pK}=\mathrm{A} 1+\mathrm{A} 2(\mathrm{~K} / \mathrm{T})+$ $\mathrm{A} 3(\mathrm{~T} / \mathrm{K})$. The values of the parameters obtained are e $\mathrm{A} 1=75.461, \mathrm{~A} 2=-7801.912, \mathrm{~A} 3=-0.1111$. The standard fit deviation is $2.175 \times 10-2$. The standard molar thermodynamic functions $\Delta \mathrm{Gm}^{\circ}, \Delta \mathrm{Hm}^{\circ}, \Delta \mathrm{Sm}^{\circ}$, for the dissociation reaction are related to the parameters of above quation.

$\Delta \mathrm{Gm}^{\circ}=\mathrm{R} \ln 10[\mathrm{~A} 1(\mathrm{~T} / \mathrm{K})+\mathrm{A} 2+\mathrm{A} 3(\mathrm{~T} / \mathrm{K}) 2]$

$\Delta \mathrm{Hm}^{\circ}=\mathrm{R} \ln 10[\mathrm{~A} 2-\mathrm{A} 3(\mathrm{~T} / \mathrm{K}) 2]$

$\Delta \mathrm{Sm}^{\circ}=-\mathrm{R} \ln 10[\mathrm{~A} 1+2 \mathrm{~A} 3(\mathrm{~T} / \mathrm{K})]$

The values of the thermodynamic function $\Delta \mathrm{Gm}^{\circ}, \Delta \mathrm{Hm}^{\circ}, \Delta \mathrm{Sm}^{\circ}$ calculated from above equations are listed in Table 
2.From Table 2. $\Delta \mathrm{Gm}^{\circ}>0$ means that the dissociation reaction can not occur spontaneously under the condition of constant temperature and pressure. The Gibbs free energy includes two factors: $\Delta \mathrm{Hm}^{\circ}$ and $\mathrm{T} \Delta \mathrm{Sm}^{\circ}$.In dissociation reaction $\Delta \mathrm{Hm}^{\circ}>\mathrm{T} \Delta \mathrm{Sm}^{\circ}$ leads us to conclude that enthalpy of dissociation is the dominant thermodynamic factor which hinders dissociation reaction from occurring. When $\mathrm{InCl} 3$ and $\mathrm{BMIC}$ quantities 1:1, [InCl4 $\left.{ }^{-}\right]$stable existence in system, namely BMIInCl4 is only pure solute in solution.

\section{References}

Dyson, P.J,Grossel, M.C., Srinivasan, N, Vine, T., Welton, T, Williams, D.J., White, J.P., Zigras, T.J. (1997). Chem.Soc. and Dalton trans. Inorg. Chem, 3465-9.

Endres, F. (2002). CHEMPHYSCHEM, 3, 144-154.

Gui, Jinsong. (2010). Properties of room temperature ionic liquid-3-ethyl-1-methylimidazolium ethyl sulfate. Russian Journal of Physical Chemistry A, Focus on Chemistry, 84(5):760-765.

Gale, R.J., Osteryoung, R.A. (1979). Inorganic Chemisty, 6, 1603-1605.

Hussey, C.L. (1988). Pure Appl.Chem., 60, 1763-1772.

Ito, Y and Vohira, T. (2000). Electrochemica.Acta, 45, 2611-22.

$\mathrm{Lu}$, Xingmei, Xu, Weiguo and Gui, insong, et al. (2005). Volumetric properties of room temperature ionic liquid 1. The system of \{1-methyl-3-ethylimidazolium ethyl sulfate + water $\}$ at temperature in the range (278.15 to 333.15 ) K.J.Chem.Thermodynamics, 37:13-19.

Sedon, KR. (1997). J, chem.. Technol.Biotechnol, 68,351-356.

Torsi, G and Mamantov, G. (1971). Inorg.Chem, 10,1900-1902.

Yang, Jiazhen, Lu, Xingmei, Gui Jinsong, et al. (2005). Volumetric properties of room temperature ionic liquid 2: The concentrated aqueous solutions of \{1-methyl-3-ethylimidazolium ethyl sulfate+water $\}$ in a temperature range of 278.2K to 338.2K.J.Chem.Thermodynamics, 2005, 37: 1250-1255.

Yang, Jiazhen, Lu, Xingmei and Gui, JinSong, et al. (2004). A new theory for ionic liquids-the Interstice Model Part 1.The density and surface tension of ionic liquid EMISE. Green Chem., 6: 541-543.

Zhang, Qingguo, Yang, Jiazhen and Lu, Xingmei, et al. (2004). Studies on an ionic liquid based on FeCl3 and its properties. Fluid Phase Equilibria., 226:207-211.

Table 1. The emf values of cell at different temperatures

\begin{tabular}{|l|l|l|l|l|l|}
\hline $\mathrm{T} / \mathrm{K}$ & 313.15 & 323.15 & 333.15 & 343.15 & 348.15 \\
\hline $\mathrm{X}(\mathrm{InCl} 3)$ & $\mathrm{E} / \mathrm{V}$ & & & & \\
0.4804 & 0.00001 & 0.000017 & 0.000016 & 0.000016 & 0.000016 \\
0.4851 & 0.04067 & 0.054961 & 0.06545 & 0.08176 & 0.09216 \\
0.4908 & 0.07742 & 0.081395 & 0.09935 & 0.097555 & 0.11321 \\
0.4950 & 0.47543 & 0.490628 & 0.50593 & 0.480828 & 0.30601 \\
0.4974 & 0.84194 & 0.860258 & 0.86880 & 0.83208 & 0.78388 \\
0.5000 & 1.00817 & 1.045791 & 1.068348 & 1.063911 & 1.0254 \\
0.5026 & 1.09712 & 1.100045 & 1.097971 & 1.076273 & 1.08171 \\
0.5051 & 1.14161 & 1.162603 & 1.156253 & 1.147941 & 1.12751 \\
0.5074 & 1.18452 & 1.182381 & 1.171732 & 1.163065 & 1.13348 \\
0.5101 & 1.19844 & 1.199988 & 1.193125 & 1.181232 & 1.15981 \\
0.5148 & 1.21745 & 1.211952 & 1.205805 & 1.194038 & 1.17421 \\
0.5201 & 1.24703 & 1.244574 & 1.242285 & 1.222213 & 1.20834 \\
0.5302 & 1.27104 & 1.267175 & 1.260243 & 1.248743 & 1.22327 \\
0.5501 & 1.32009 & 1.321288 & 1.321745 & 1.309425 & 1.28269 \\
\hline
\end{tabular}

Table 2. The values of thermodynamic function for dissociation reaction at different Temperatures

\begin{tabular}{|l|l|l|l|l|l|}
\hline $\mathrm{T} / \mathrm{K}$ & 313.15 & 323.15 & 333.15 & 343.15 & 348.15 \\
\hline$\Delta \mathrm{Gm}^{\circ} / \mathrm{kJ} . \mathrm{mol}-1$ & 88.22 & 89.01 & 88.45 & 88.15 & 88.00 \\
\hline$\Delta \mathrm{Hm}^{\circ} / \mathrm{kJ} . \mathrm{mol}-1$ & 108.91 & 94.67 & 79.63 & 66.24 & 59.04 \\
\hline$\Delta \mathrm{S} \mathrm{m}^{\circ} / \mathrm{J} . \mathrm{K}-1 \mathrm{~mol}-1$ & 60.12 & 16.06 & -27.64 & -72.60 & -96.50 \\
\hline
\end{tabular}

